\title{
Estimating tropical rain attenuation on the Earth- satellite path using radar data
}

\section{Khairayu Badron, Ahmad Fadzil Ismail \& Maszlan Ismail}

To cite this article: Khairayu Badron, Ahmad Fadzil Ismail \& Maszlan Ismail (2015) Estimating tropical rain attenuation on the Earth-satellite path using radar data, International Journal of Remote Sensing, 36:24, 6101-6115, DOI: 10.1080/01431161.2015.1111538

To link to this article: http://dx.doi.org/10.1080/01431161.2015.1111538

册 Published online: 24 Nov 2015.

Submit your article to this journal $\sqsubset \pi$

山 Article views: 39

Q View related articles $\asymp$

View Crossmark data ¿ 


\title{
Estimating tropical rain attenuation on the Earth-satellite path using radar data
}

\author{
Khairayu Badron $^{\mathrm{a} *}$, Ahmad Fadzil Ismail ${ }^{\mathrm{a}}$, and Maszlan Ismail ${ }^{\mathrm{b}}$ \\ ${ }^{a}$ ECE Dept, Faculty of Engineering, International Islamic University Malaysia, 50728 Kuala \\ Lumpur, Malaysia; ${ }^{b}$ National Space Centre, Kuala Lumpur, Malaysia
}

(Received 1 April 2015; accepted 18 October 2015)

\begin{abstract}
Radar-return echoes, known as 'reflectivity', are exploited in the course of estimating rain attenuation along a slant path. Relevant radar gates or 'range bins' are identified to correlate a specific satellite path. The reflectivity value of each range bin is converted to rainfall rate using established radar reflectivity values - rainfall rates, $(Z-R$ relation). Specific attenuation is then derived for all associated range bins. The attenuation for each bin is the product of specific attenuation and its effective path length. The summation of attenuation endured by all range bins is inferred as the attenuation along the slant path. In this study, an X-band slant path rain attenuation was estimated using 2.85 GHz (S-band) Terminal Doppler Weather Radar (TDWR) data. A technique to estimate rain attenuation by exploitation of radar information is elaborated in this article. Comparisons between the radar-derived attenuation estimations and actual satellite signal measurements are also presented. The findings were verified by comparing the generated values to the directly measured rain attenuation from the Razak satellite (RazakSAT). Radar reflectivity data were obtained from Kuala Lumpur International Airport (KLIA) radar station operated by the Malaysian Meteorology Department (MMD). Preliminary findings using the most recent $Z-R$ relation (i.e. the generated radar-derived rain attenuation estimations) appear to show lower values than the actual measurements.
\end{abstract}

\section{Introduction}

The knowledge of rain fade level at a specific frequency of operation is critical in the design of a reliable terrestrial and/or Earth-space communication link. Satellite transmissions at operating frequencies of super-high frequency (SHF) and above suffer from severe signal attenuation mainly due to rain (Badron et al. 2009; Goldhirsh 1976). In tropical countries, Malaysia included, excessive rainfall is a frequent phenomenon throughout the year (Dao et al. 2012). It is critical to be able to accurately predict the potential impairment due to rain that may be encountered on any given link (Bech et al. 2012). Development of a dedicated Earth-space communication link exclusively for the purpose of propagation research can indeed be very expensive. One potential strategy in identifying the likely attenuation due to rain is by acquiring detailed statistical description in terms of its horizontal and vertical structure. Radio detection and ranging (radar), developed initially for aircraft detection during World War II, was soon applied to tracking rainfall from radar echo reflectivity values (Roland 2000). Most weather radars can perform measurement of rain's spatial structure (Stutzman et al. 1989). Observation data generated by radar operating in volume-scan surveillance mode can be used in rain

*Corresponding author. Email: khairayu@gmail.com 
attenuation estimation, because the data give spatial and temporal information relating to the precipitation process. The information provided by radar can play an important role in the estimation of rain-induced propagation effects (Rinehart 2001). Radar reflectivity data therefore represent an attractive alternative for rain attenuation estimation. Weather radar is likely to be deployed near main airports to assist air traffic controllers by providing detection of real-time wind shear, as well as information on high-resolution precipitation.

\section{Measurement set-up and data configuration}

\subsection{Radar system}

A Terminal Doppler Weather Radar (TDWR) system is currently installed at Bukit Tampoi, about $10 \mathrm{~km}$ north of Kuala Lumpur International Airport (KLIA) for the detection and warning of wind shear and microburst. The S-band radar is located at $2^{\circ}$ $45^{\prime} 0^{\prime \prime} \mathrm{N} / 101^{\circ} 42^{\prime} 0.1^{\prime \prime} \mathrm{E}$ and operates at a frequency of $2.85 \mathrm{GHz}$. The radar system is programmed to operate in two scanning modes - airport and aerial. The radar automatically shifts from aerial to airport mode when its sensor detects rainfall above $0.1 \mathrm{~mm} \mathrm{~h}^{-1}$ within the $20 \mathrm{~km}^{2}$ of KLIA. Both modes consist of three different volume scans called TASKs. Volume A (Vol A) is used for long-range observation at low elevation angles, Volume B (Vol B) is for medium-range observation, and Volume C (Vol-C) is for shortrange observation at high elevation angles. Both the pulse repetition frequency (PRF) and antenna scan rate are different for each task; higher PRF is used in the short-range mode. Approximately 300 volume raster scans are acquired per day, whereby each scan is generated within a duration of about 5 minutes. Calibration of TDWR radar by Enterprise Electronics Corporation (EEC), USA is carried out twice per year, in July and December. The local company contracted to perform the task is Malaysia Airport Technologies Sdn. Bhd, one of the subsidiaries of Malaysia Airport Holdings Berhad. The document ISO/IEC 17,025 pertaining to 'General Requirements for the Competence of Testing and Calibration' is followed during the process. Both transmitted and received signal power are verified with the use of testing instruments, namely oscilloscope, power meter, power sensor, frequency counter, signal generator, spectrum analyser, attenuators, and crystal detectors. Data were acquired from 1 January to 31 December 2009. Ideally, radar scans of 1 minute should be used, but the present system requires 10 sweeps, so 5 minutes is required in order to be able to generate a full-volume scan. This is the only available data option that can be acquired from the Malaysia Meteorology Department (MMD). Should 1-minute scanning data become available in the future, a more refined technique can be utilized. Figures 1 and 2 show the information provided by the MMD, and Table 1 lists the radar characteristics. An IRIS software system provided by Vaisala is used to generate and display TDWR information. Reflectivity, $Z$ can vary from extremely high values for heavy rain to very low values for mist. For viewing of this wide range of $Z$ on a computer screen, the software converts values to logarithmic amounts which are expressed in units of decibels (dBZ). The reflectivity, $Z$ in unit $\mathrm{dB} Z$ is calculated from (1):

$$
\mathrm{dB} Z=10 \log _{10} Z\left(\mathrm{~mm}^{6} \mathrm{~m}^{-3}\right) .
$$

The IRIS system incorporates Gaussian Model Adaptive Processing (GMAP), the most advanced form of clutter filtering and moment estimation for anomalous propagation. The algorithms include data quality thresholds such as: 


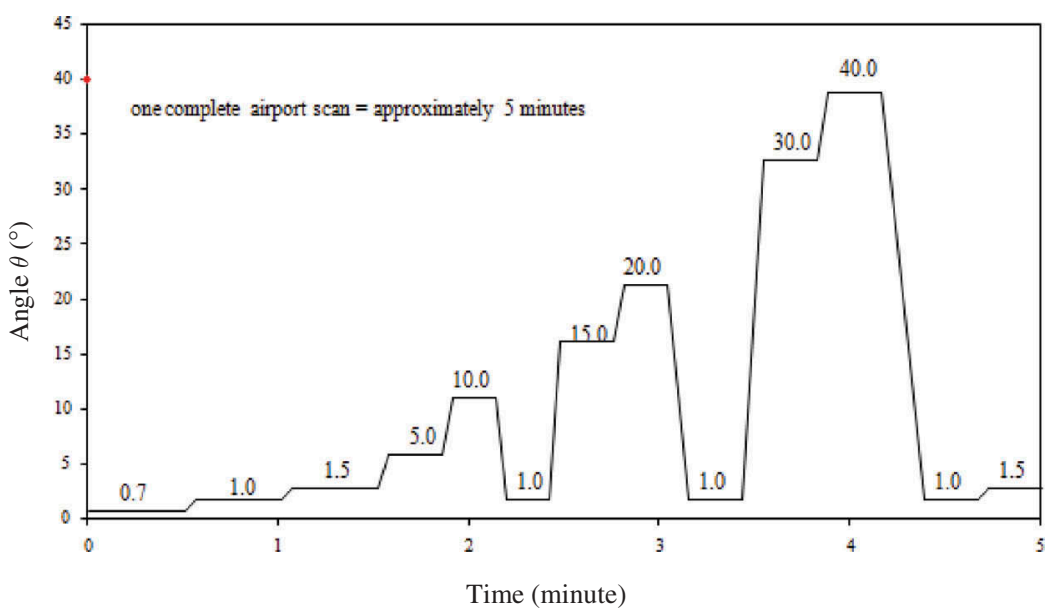

Figure 1. Airport mode radar scanning configuration.

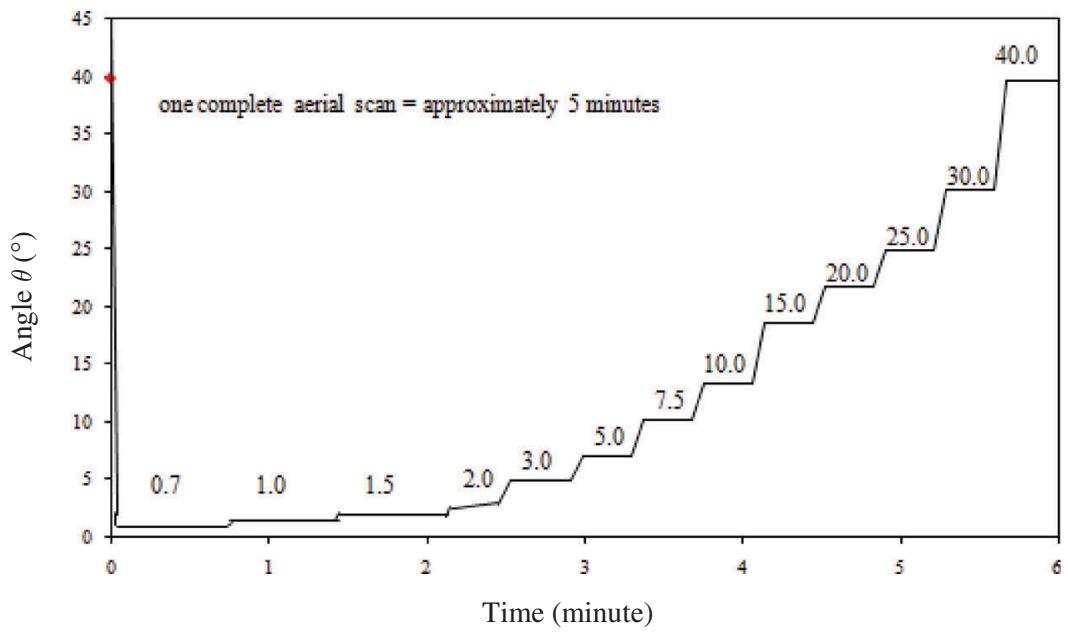

Figure 2. Aerial mode radar scanning configuration.

(1) Signal-to-noise ratio (SNR) - to reject bins with a weak signal;

(2) Signal Quality Index (SQI) - to reject bins with an incoherent signal;

(3) Clutter-to-signal ration (CSR) - to reject range bins with very strong clutter;

(4) Speckle Filter - to remove single bin targets such as aircraft or noise.

The values of $\mathrm{dBZ}$ obtained are already clutter-corrected reflectivity. Further details of these algorithms are given in the IRIS/Open user's manual, version 7.05 (SIGMET 1999).

\subsection{RazakSAT satellite system}

QPSK modulated X-band $(8.21 \mathrm{GHz})$ transmission signals from the Razak satellite (RazakSAT) were received, monitored, and tracked by the Hexapod antenna located at 
Table 1. Radar specifications.

\begin{tabular}{|c|c|c|}
\hline Tasks & Aerial scan & Airport scan \\
\hline Elevation angles $\left({ }^{\circ}\right)$ & $\begin{array}{l}0.7,1.5,2.0,3.0 \\
\quad 5.0,7.5,10.0,15.0,20.0,25.0 \\
\quad 30.0,40\end{array}$ & $0.7,1.0,1.5,5.0,10.0,05.0,20.0,30.0,40.0$ \\
\hline PRF (Hz) & 300 (Vol A) /1000 (Vol B \& C) & $300($ Vol A) $/ 1000($ Vol B \& C) \\
\hline Pulse width (s) & $3 \mu(\operatorname{Vol} A) / 1 \mu(\operatorname{Vol} B$ B \& C $)$ & $3 \mu(\operatorname{Vol} \mathrm{A}) / 1 \mu(\mathrm{Vol} \mathrm{B} \& \mathrm{C})$ \\
\hline RPM & $2(\mathrm{Vol} \mathrm{A}) / 4(\mathrm{Vol} \mathrm{B} \& \mathrm{C})$ & $2(\mathrm{Vol} \mathrm{A}) / 4(\mathrm{Vol} \mathrm{B} \& \mathrm{C})$ \\
\hline Max range $(\mathrm{km})$ & $480($ Vol A $) / 128($ Vol B \& C $)$ & $480($ Vol A $) / 240($ Vol B \& C) \\
\hline Reflector diameter (m) & 8.5 & 8.5 \\
\hline Freq $(\mathrm{MHz})$ & 2874.5 & 2874.5 \\
\hline Wavelength, $\mu(\mathrm{cm})$ & 10.43 & 10.43 \\
\hline Polar & Vertical & Vertical \\
\hline Radome diameter (m) & 12 & 12 \\
\hline
\end{tabular}

$2^{\circ} 47^{\prime} 3^{\prime \prime} \mathrm{N} / 101^{\circ} 30^{\prime} 27^{\prime \prime} \mathrm{E}$. The RazakSAT satellite is operated and controlled from its ground station at Sungai Lang, Banting, Selangor, Malaysia. The ground segment (i.e. Malaysian Space Centre (ANGKASA)) consists of a Mission Control Station (MCS) and an Image Receiving and Processing Station (IRPS). The RazakSAT mission plan, command generation, and telemetry receiving, archiving, and analysis were executed at the MCS by a dedicated team of engineers. The satellite orbits the Earth in a unique positioning identified as near equatorial orbit (NEqO) at an altitude of approximately $685 \mathrm{~km}$. This is especially important because Malaysia is usually covered by equatorial cloud bands. Normal sun-synchronous optical satellites, which revisit an area once every 7 days, rarely observe the ground during their pass (RazakSAT 2006). In contrast, RazakSAT revisited parts of Malaysian territory almost every 90 minutes. The elevation angles involved range from $0^{\circ}$ to $89^{\circ}$. Table 2 summarizes selected configuration satellite details. In the rain attenuation analysis, specific elevation angles were processed accordingly. Figure 3 shows an example of a recorded RazakSAT satellite pass. It will be observed that the elevation angles involved are in the range $0-80^{\circ}$. The data were acquired on 21 July 2009, from 7:53:46 to 8:07:39. The satellite was in contact with the ground station for about 20 minutes and passed through the Malaysian atmosphere 14 times daily. During these critical hours, the signal power level received at the ground station was measured. First, all rainy events were identified. The elevation angle, latitude, and longitude were then recorded. Next, the values of signal power received at the same elevation

Table 2. RazakSAT specifications.

\begin{tabular}{ll}
\hline Item & \multicolumn{1}{c}{ Specifications } \\
\hline Orbit & Near Equatorial Low Earth Orbit (NeqO) \\
Altitude & $685 \mathrm{~km}$ \\
Mass & $187.6 \mathrm{~kg}$ \\
Envelope & $\mathrm{f} 1200 \mathrm{~mm}{ }^{\prime} \mathrm{H} 1200 \mathrm{~mm}$ \\
Attitude Control Accuracy & $0.2^{\circ}$ \\
Power & $>300 \mathrm{~W}$ \\
Payload & Medium-sized Aperture Camera \\
Mass Storage Capacity & 32 Gbits \\
Data Down Link & 30 bps (X-Band) \\
\hline
\end{tabular}




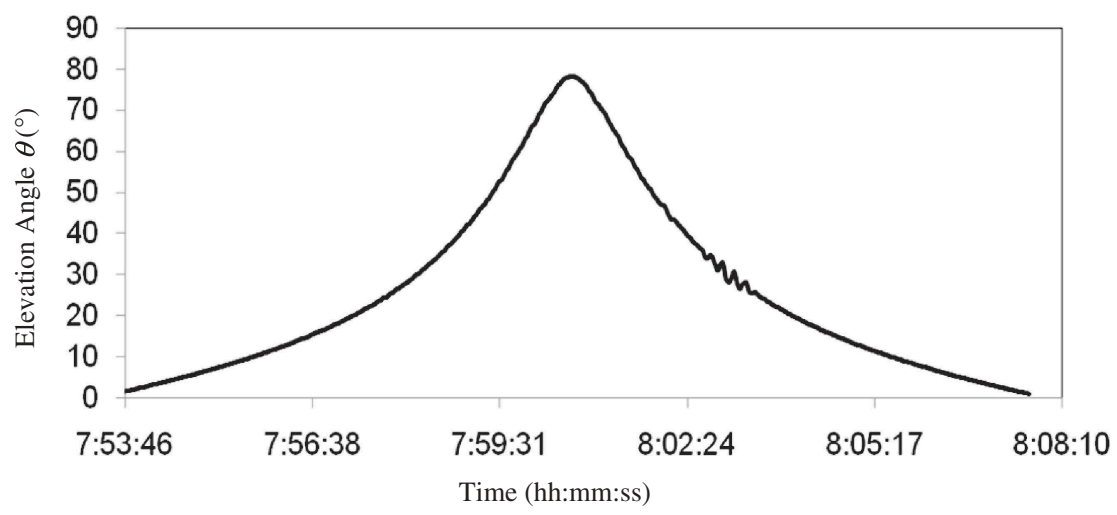

Figure 3. Elevation angles of RazakSAT during pass on 2 July 2009 at 7:53:46-8:07:39.

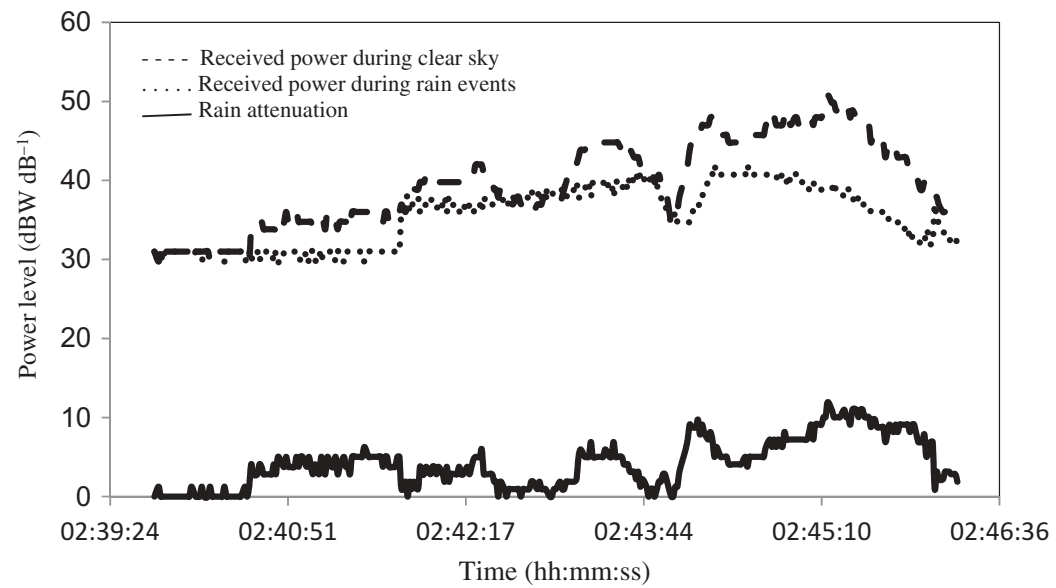

Figure 4. Power level differences during clear sky and rainy events and rain attenuation on 21 July 2009 at $2: 39: 24-2: 46: 36$.

angle, latitude, and longitude under clear skies were retrieved. The signal power received during rain was then subtracted from that received under clear skies, and the difference was implied as rain attenuation. The data set thus acquired covers a 6-month period from 1 June 2009. Figure 4 shows examples of the received power level under clear skies and during a rain event, and the calculated rain attenuation. The event was recorded on 21 July 2009 at about 2:39:24.

\section{Estimating rain attenuation using radar data}

\subsection{Selection of $Z-R$ relation}

In the study of radar meteorology, the accurate determination of rainfall rate from measured reflectivity is highly critical. Radar reflectivity values - rainfall rates $(Z-R$ relation) - associate the value of measured reflectivity to that of the rainfall rate. Rainfall rate $(R)$ can be defined as the rate of increase of depth of water, measured in $\mathrm{mm} \mathrm{h} \mathrm{h}^{-1}$. Over the years, several different $Z-R$ relationships had been developed and 
proposed. These are mostly empirical models that were developed using co-located and simultaneous rainfall rate measurements and radar reflectivity measurements. There is significant variability in the suggested models (Battan 1973; Doviak and Zrnic 1993). It has been highlighted that the $Z-R$ relation may be site-specific and is not applied universally in different locations around the world (Savageot 1992; Marshal and Palmer 1948). Pioneer investigators such as Marshal and Palmer (1948) published their $Z-R$ relation with a set of generic parameters $(a=200$ and $b=1.6)$. Battan (1973) on the other hand, presented a list with 69 different $Z-R$ relations for different climatic conditions in different parts of the world. In the past, research work was carried out in an attempt to improve the applicability of $Z-R$ relations by classifying rain into different types (Tokay and David 1995). Many studies have demonstrated that widespread rain, typically labelled as stratiform rain, is characterized by smaller raindrop diameter relative to thunderstorm rain, commonly known as convective rain, for the same liquid water content (Wilson and Tan 2001). Rainfall rates of less than $1.5 \mathrm{~mm} \mathrm{~h}^{-1}$ are classified as stratiform rain whereas higher rates are regarded as convective rain (Wilson and Tan 2001). Rainfall rates are commonly accepted as deviating considerably from one specific region to another. In regard to the present work, several $Z-R$ relationships claimed to be applicable to tropical climates have been taken into consideration. Ladd, Wilson, and Thurai (1997) and Ismail (2001) proposed $Z-R$ relations for tropical climates using data acquired from Papua New Guinea. Wilson and Tan (Wilson and Tan 2001) used radar data and distrometer data to derive $Z-R$ relations for Singapore, while Kumar et al. (2011) proposed a revised general $Z-R$ relation for that country. Table 3 shows the parameters of selected $Z-R$ relations.

Yeo et al. (2012) had identified that the root mean square (RMS) error between beacon measurements and radar-estimated attenuation using the $Z-R$ relation proposed by Kumar et al. (2011) is the smallest compared to that of others. Due to climatic similarity and the short distance of about $200 \mathrm{~km}$ between Singapore and our location of interest (Kuala Lumpur), the $Z-R$ relation proposed by Kumar et al. (2011) is adopted in this analysis.

\subsection{Technique for estimating satellite rain attenuation}

One year (2009) of full volumetric radar echo reflectivity data were used for rain attenuation approximation. The procedure is explained below;

Step 1:

Raw radar data for the specific time range and location were acquired and ingested using the IRIS software. Rainy conditions were confirmed using the rain gauge installed at the KLIA. All dates and times where rain gauge data including values of more than $0.1 \mathrm{~mm} \mathrm{~h}^{-1}$ were inspected. Figure 5 shows the location map of the KLIA radar stations

Table 3. $Z-R$ relation parameters.

\begin{tabular}{|c|c|c|c|c|c|}
\hline \multirow[b]{2}{*}{ Location } & \multirow[b]{2}{*}{ References } & \multicolumn{2}{|c|}{ Convective } & \multicolumn{2}{|c|}{ Stratiform } \\
\hline & & $a$ & $b$ & $a$ & $b$ \\
\hline Singapore & Kumar et al. (2011) & 285 & 1.33 & 285 & 1.33 \\
\hline Singapore & Wilson and Tan (2001) & 139 & 1.50 & 330 & 1.35 \\
\hline Papua New Guinea & Ladd, Wilson, and Thurai (1997) & 93 & 1.36 & 132 & 1.36 \\
\hline Kalingamari & Tokay and David (1995) & 139 & 1.43 & 367 & 1.30 \\
\hline Ottawa & Marshal and Palmer (1948) & 200 & 1.6 & 200 & 1.6 \\
\hline
\end{tabular}




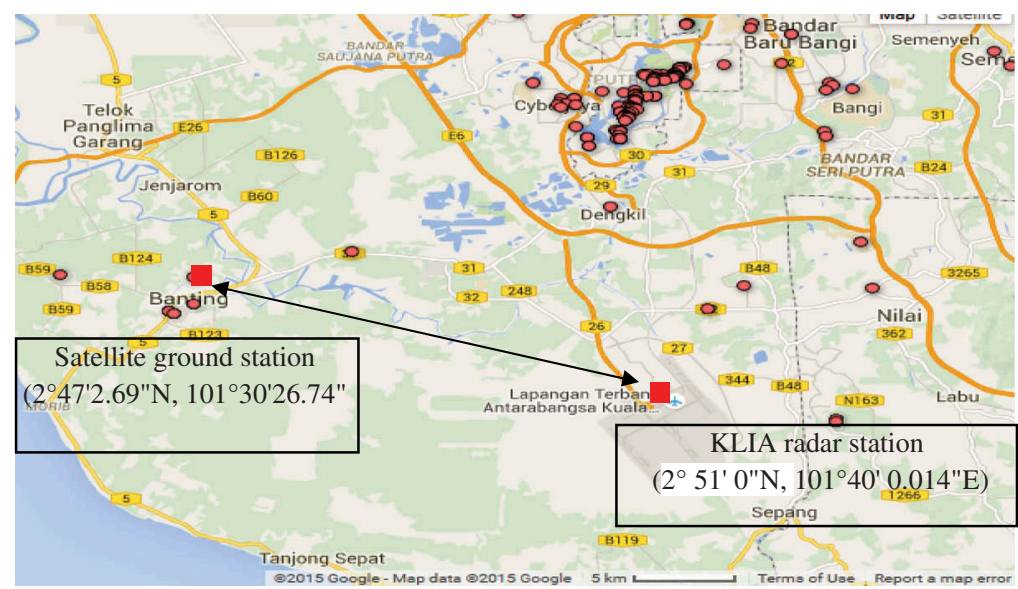

Figure 5. Location map of KLIA radar and the satellite ground station.

Table 4. TDW radar and satellite ground station location, bearings, and distance.

\begin{tabular}{lllll}
\hline & Latitude & Longitude & Bearing & Distance \\
\hline Satellite Ground Station, Banting & $2^{\circ} 47^{\prime} 2.69^{\prime \prime} \mathrm{N}$ & $101^{\circ} 30^{\prime} 26.74^{\prime \prime}$ & $247^{\circ} 29^{\prime} 30^{\prime \prime}$ & $19.4 \mathrm{~km}$ \\
KLIA Radar Station & $2^{\circ} 51^{\prime} 0^{\prime \prime} \mathrm{N}$ & $101^{\circ} 40^{\prime} 0.014^{\prime \prime} \mathrm{E}$ & & \\
\hline
\end{tabular}

and the satellite ground station. Bearings and distances were calculated using the latitude and longitude of the two sites. Table 4 lists the latitude, longitude, and bearings information.

Step 2:

In order to determine the rain attenuation of the satellite path, the associated satellite path route was drawn on the plan position indicator (PPI) display. The azimuth angle, $\phi$ from the ground station to the satellite depicted in horizontal view (PPI) is shown in Figure 6 . The cross-section of the satellite path on the vertical plane, known as the range height indicator (RHI), was generated in order to distinguish rainfall rate features. The RHI display was then analysed to extract rain characteristics. The image of the crosssection of the satellite path in Figure 6 is shown in Figure 7.

Step 3:

The values of the height from the ground, $z$ azimuth angle $\phi$, and the distances, $x$ and $y$, from the ground station were acquired in the estimation technique. The $x$ and $y$ values were obtained based on latitudes and longitudes of the two points using the 'haversine' formula to calculate the great-circle distance. The technique adapted from Mohr and Vaughan (1979) to estimate equivalent radar reflectivity in an orthogonal coordinate system was used in the application to calculate rain attenuation for the Earth-space link. The desired Cartesian coordinate system $(x, y, z)$ was defined and converted to effective path length, $L_{\mathrm{e}}$, elevation angle, $\theta$, and azimuth angle, $\phi$ according to the relations:

$$
L_{\mathrm{e}=\sqrt{x^{2}+y^{2}+z^{2}}},
$$




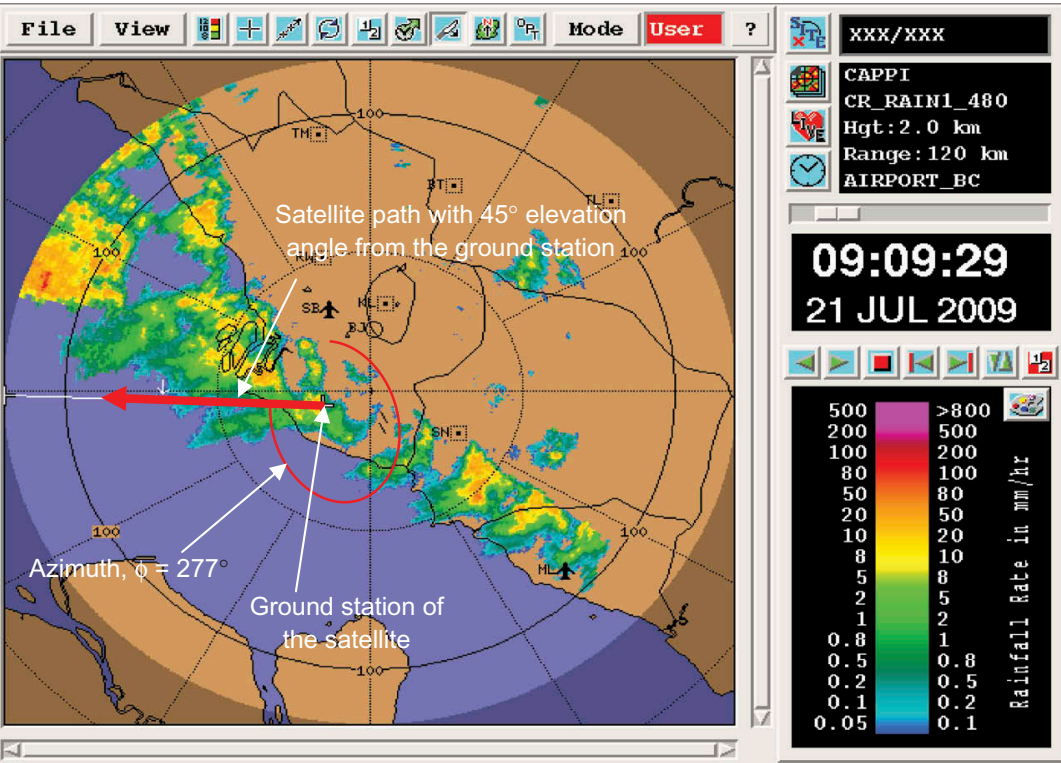

Figure 6. Ground station location, satellite path link, and azimuth angle from the ground station to the satellite.

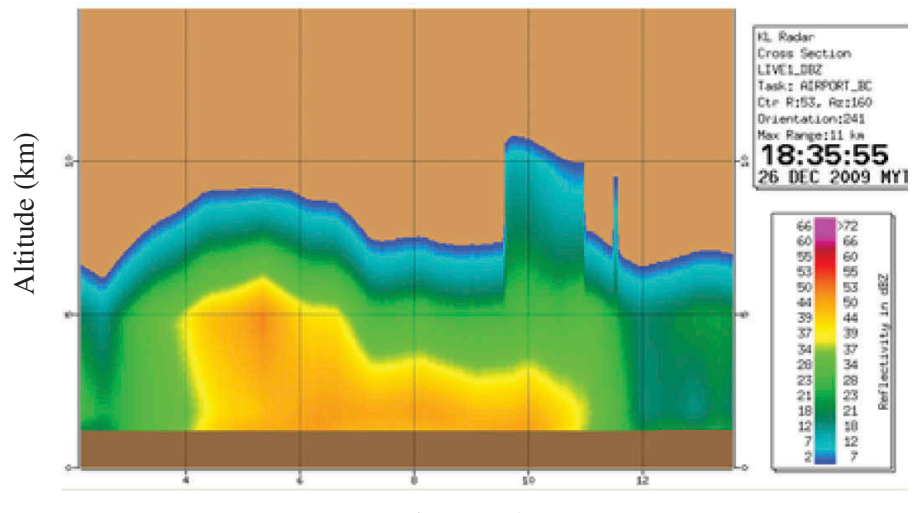

Distance $(\mathrm{km})$

Figure 7. Example of the RHI image of the satellite path at the specified time and angle based on the RazakSAT databases.

$$
\phi=\tan ^{-1} \frac{x}{y}
$$

where the satellite ground station is the origin. Figure 8 shows the Cartesian coordinates with reference to the Earth-space link. Standard adjustment was made in the calculation of the elevation angle, $\theta$ to take into account the Earth's curvature and beam refraction (Mohr and Vaughan 1979). The height of a given point $(x, y, z)$ above the perceived horizon, $z_{\mathrm{h}}$ was computed using Equation (4): 


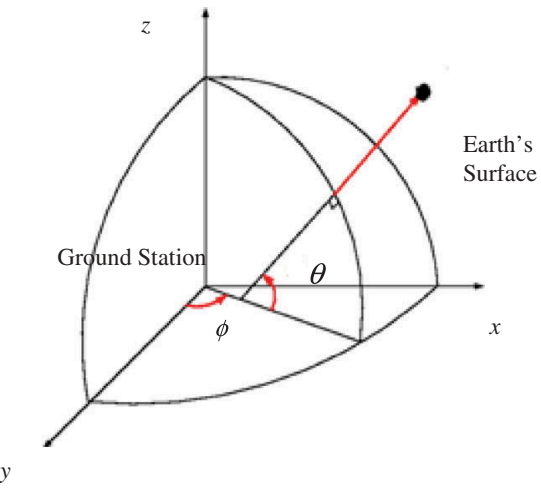

Figure 8. The structure of the Earth-space link projected to Cartesian coordinates to assist in radar data estimation.

$$
z_{\mathrm{h}}=z-\frac{x^{2}-y^{2}}{i D}
$$

where $i$ is the standard compensating factor (1.33) for beam refraction in the troposphere

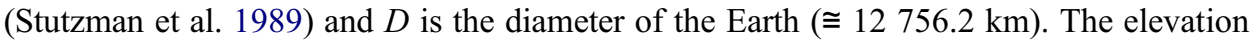
angle, $\theta$ was then computed as:

$$
\theta=\sin ^{-1} \frac{z_{\mathrm{h}}}{L_{\mathrm{e}}}
$$

Step 4:

After production of the cross-section based on the coordinates, the subsequent product generated by the IRIS software is identified as 'productx'. Productx displays the data in 1byte reflectivity format, generated from radar reflectivity values derived from pixels of the cross-sectional views. The typical colour bar in PPI and RHI comprises only 16 levels for ease of display. Productx is actually capable of providing the reflectivity values for each range bin without involving any interpolation. For the analysis involved, the bin size is $119 \mathrm{~m} \times 23.8 \mathrm{~m}$. Once the productx along the satellite path is generated, the actual $\mathrm{dBZ}$ value in each range bin for the cross-sectional product is then available for further processing.

Step 5:

Figure 9 shows the selected event with satellite path link at $45^{\circ}$ elevation angle from the ground station viewed in the cross-sectional scan form. Figure 8 shows productx's reflectivity values originating from the red square shown in Figure 9 - a small fraction of the total path. The relevant range bins depend on the elevation angle of the satellite path link, as shown in Figure 10.

Step 6:

The reflectivity values (in $\mathrm{dBZ}$ ) were then converted to rainfall rate according to the $Z-R$ relationship proposed by Kumar et al. (2011):

$$
Z=a R^{b}
$$

with radar reflectivity factor $Z\left(\mathrm{~mm}^{-6} \mathrm{~m}^{3}\right)$ and rain rate $R\left(\mathrm{~mm} \mathrm{~h}^{-1}\right)$. The $Z-R$ relation uses a set of general parameters with $a=285$ and $b=1.33$ for both convective and stratiform 


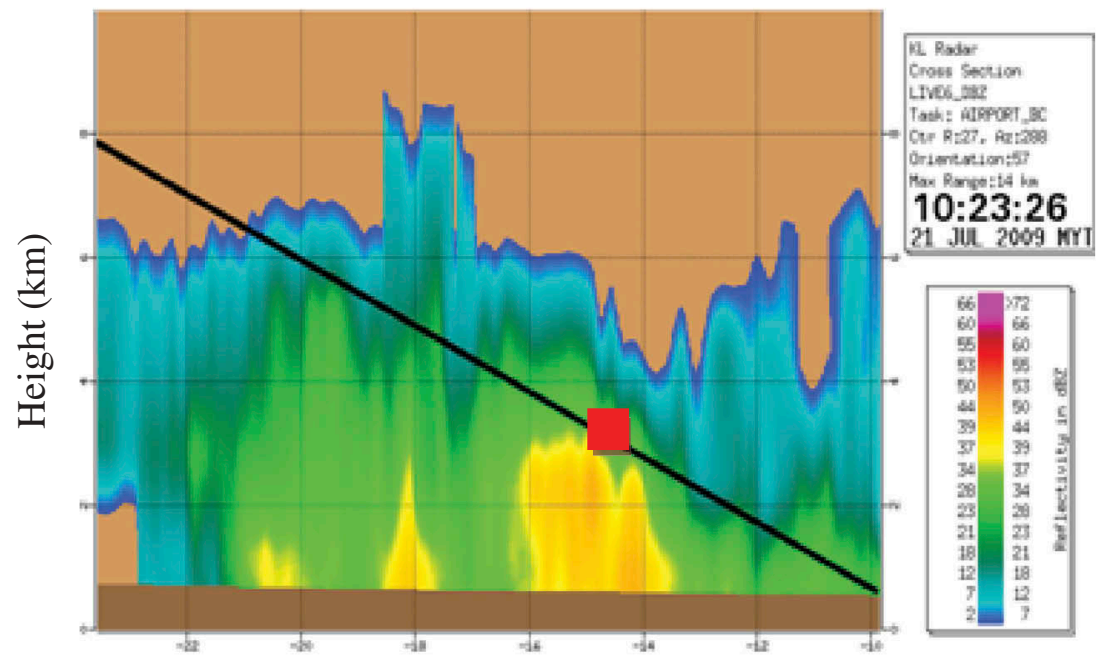

Distance $(\mathrm{km})$

Figure 9. Satellite path link previewed in XSECT product at $45^{\circ}$ elevation angle from the satellite ground station.

\begin{tabular}{|c|c|c|c|c|c|c|c|c|c|c|c|c|}
\hline 14 & 54 & 57 & 59 & 61 & 63 & 65 & 67 & 70 & 71 & 72 & 72 & 71 \\
\hline 13 & 55 & 58 & 60 & 62 & 64 & 66 & 68 & 71 & 72 & 73 & 73 & 71 \\
\hline 12 & 55 & 59 & 61 & 63 & 65 & 67 & 69 & 72 & 73 & 74 & 74 & 72 \\
\hline 11 & 56 & 59 & 62 & 64 & 66 & 68 & 70 & 72 & 74 & 75 & 74 & 73 \\
\hline 10 & 57 & 60 & 63 & 65 & 66 & 68 & 71 & 73 & 75 & 76 & 75 & 74 \\
\hline 8 & 58 & 61 & 63 & 65 & 67 & 69 & 72 & 74 & 76 & 77 & 76 & 75 \\
\hline$\Xi$ & 58 & 62 & 64 & 66 & 68 & 70 & 73 & 75 & 77 & 78 & 77 & 75 \\
\hline$\Xi$ & 59 & 62 & 65 & 67 & 69 & 71 & 74 & 76 & 78 & 78 & 78 & 76 \\
\hline \multirow{6}{*}{$\Xi$} & 60 & 63 & 66 & 68 & 70 & 72 & 74 & 77 & 79 & 79 & 79 & 77 \\
\hline & 60 & 64 & 67 & 69 & 71 & 73 & 75 & 78 & 80 & 80 & 79 & 78 \\
\hline & 61 & 65 & 67 & 70 & 71 & 74 & 76 & 79 & 80 & 81 & 80 & 79 \\
\hline & 62 & 65 & 68 & 70 & 72 & 74 & 77 & 79 & 81 & 82 & 81 & 79 \\
\hline & 63 & 66 & 69 & 71 & 73 & 75 & 78 & 80 & 82 & 83 & 82 & 80 \\
\hline & 63 & 67 & 70 & 72 & 74 & 76 & 79 & 81 & 83 & 84 & 83 & 81 \\
\hline
\end{tabular}

Figure 10. 'Productx'-derived $\mathrm{dB} Z$ for reflectivity values from XSECT product.

events. By rearranging the formulation, the value of rainfall rate was inferred from the value of measured reflectivity as in Equation (7):

$$
R=\sqrt[b]{\frac{Z}{a}}
$$

Higher values of $\mathrm{dBZ}$ typically correspond to heavier rainfall from more intense thunderstorms, while low values correspond to light rain from shallow clouds. An approximate relationship between $\mathrm{dB} Z, R$, and descriptive intensity is given in Figure 11.

Step 7:

Once the rainfall rate was calculated, the specific rain attenuation, $\gamma_{i}\left(\mathrm{~dB} \mathrm{~km}^{-1}\right)$ for each specific range bin $\left(i^{\text {th }}\right)$ was then determined using Equation (8): 


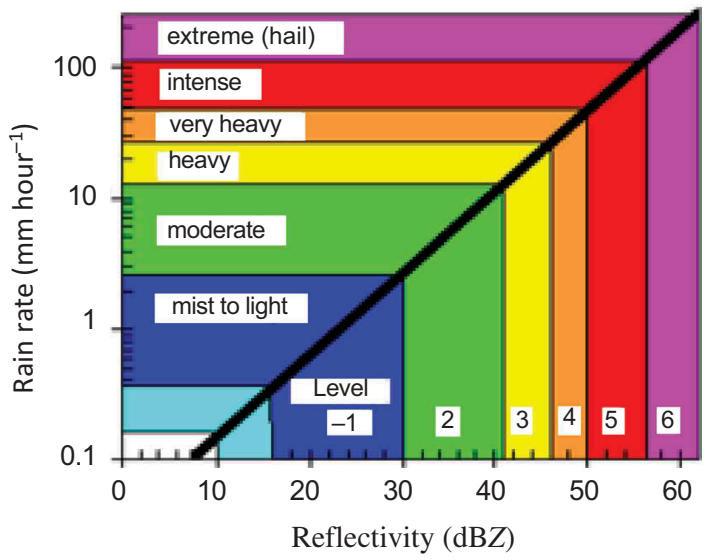

Figure 11. Rain intensity level derived from reflectivity values (Roland 2000).

$$
\gamma_{i}=k R_{i}^{\alpha}
$$

where $R_{i}$ is the rainfall rate at the indicated bin, and the coefficients $k$ and $\alpha$ were obtained from the International Telecommunication Union Recommendation (ITU-R) Rec. P.838-3 (2005) and are dependent on the link elevation angle $(\theta)$, radiowave frequency, and polarization tilt angle relative to the horizontal $(\tau)$ :

$$
\begin{gathered}
k=\left[k_{\mathrm{H}}+k_{\mathrm{V}}+\left(k_{\mathrm{H}}-k_{\mathrm{V}}\right) \cos ^{2} \theta \cos 2 \tau\right] / 2, \\
\alpha=\left[k_{\mathrm{H}} \alpha_{\mathrm{H}}+k_{\mathrm{V}} \alpha_{\mathrm{V}}+\left(k_{\mathrm{H}} \alpha_{\mathrm{H}}-k_{\mathrm{V}} \alpha_{\mathrm{V}}\right) \cos ^{2} \theta \cos 2 \tau\right] / 2 k,
\end{gathered}
$$

where the constants for the coefficient $k_{\mathrm{H}}$ for horizontal polarization, $k_{\mathrm{V}}$ for vertical polarization, $\alpha_{\mathrm{H}}$ for horizontal polarization, and $\alpha_{\mathrm{V}}$ for vertical polarization are given in the recommendation. The values 0.0041 and 1.391 correspond to $k$ and $\alpha$, respectively, which was extrapolated using values suggested by ITU-R Rec. P.838-3 for the link at $8.21 \mathrm{GHz}$. The conversion of rain rate to specific attenuation was carried out using regular power-law relationships. The coefficients $k$ and $\alpha$ rely not only on frequency, polarization, and link elevation, but also on drop size distribution (DSD). Kumar et al. (2011) suggested that the truncated gamma DSD model is more appropriate for tropical regions based on studies carried out in Singapore. The use of ITU-R-derived coefficients in the proposed technique is indeed in contrast to the employment of the $Z-R$ relationship derived by Kumar et al. (2011), because the two equations were obtained from different DSDs. Exhaustive inspection was carried out and yet no derivation of $k$ and $\alpha$ for tropicals region for truncated gamma DSD can be found. Therefore, ITU parameters were adopted. Concurrent research undertakings involve new derivation of applicable $k$ and $\alpha$ for the $8.21 \mathrm{GHz}$ link. This will be achieved by exploiting existing measured attenuation data against the measured rainfall rate from a co-located rain gauge.

The rain attenuation for each range bin $A_{i}(\mathrm{~dB})$ was then calculated by:

$$
A_{i}=\gamma_{i} L_{\mathrm{e}, i}
$$




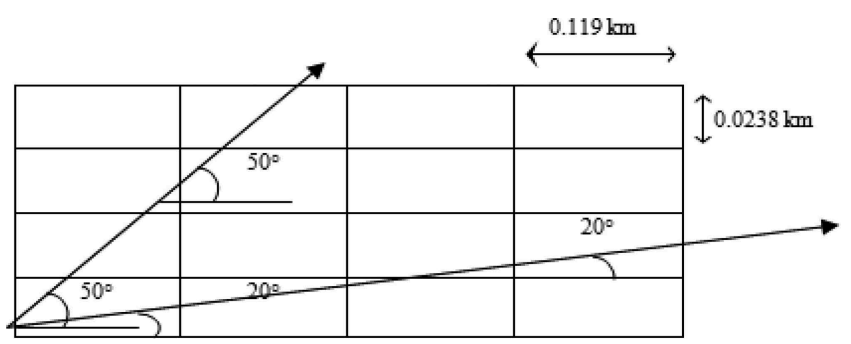

Figure 12. Bin angle configuration used to calculate the effective path length, $L_{\mathrm{e}, i}$.

where $L_{\mathrm{e}, i}$ is the affected path length within the range bins. $L_{\mathrm{e}, i}$ is calculated based on the elevation angle $(\theta)$ from the Earth station to the satellite for each bin. Therefore $L_{\mathrm{e}, i}(\mathrm{in} \mathrm{km})$ for each bin is equal to:

$$
L_{\mathrm{e}, i}=\frac{0.0238}{\sin (\theta)}=\csc (\theta) \times 0.0238 .
$$

Figure 12 shows the elevation angle affecting the bin's path length.

Total rain attenuation along the slant path, $A_{\text {total }}$ was then calculated through the numerica summation of (9):

$$
A_{\text {total }}=\sum_{i=0}^{n} A_{i},
$$

where $i$ is the number of bins affected by rain and $n$ is the corresponding number based on elevation angle.

In radar data of 5-minute sampling time, several readings from different angles can be derived. During 6 months of satellite signal measurement, 68 days were identified as rainy. There were 168 events and 742 samples in total. All 742 samples were analysed in this study. The mean RazakSAT link rain attenuation from $0^{\circ}$ elevation angles with intervals of $5^{\circ}$ is denoted by a dashed line in Figure 13. The average radar-derived rain attenuation is plotted as the blue line in the same figure. Kumar (2009) proposed the calculation of slant path attenuation exceeding $1 \%$ of the time for several frequencies for $R_{0.01}$ equal to $120.30 \mathrm{~mm} \mathrm{~h}^{-1}$ using ITU-R P.618-9 (International and Telecommunication Union 2012). Kumar (2009) also calculated rain attenuation for a satellite link at different elevation angles using the ITU-R procedure; the findings were suggested to be applicable to Singapore, which is also located in a tropical region. ITU-R P.618-12 (2012) calculation for Kuala Lumpur was also carried out and an additional plot is included in Figure 13. The measured slant-path rain attenuation for the X-band is plotted in the same figure. The values derived from radar data appear to be lower than those measured by RazakSAT for rain attenuation. ITU-R estimations also show lower values than those of measured RazakSAT rain attenuation. The assessment of both rain attenuation values was further investigated by determination of standard deviation (SD) and percentage error of rain. The relevant $\mathrm{SD}$ in this study is defined as: 


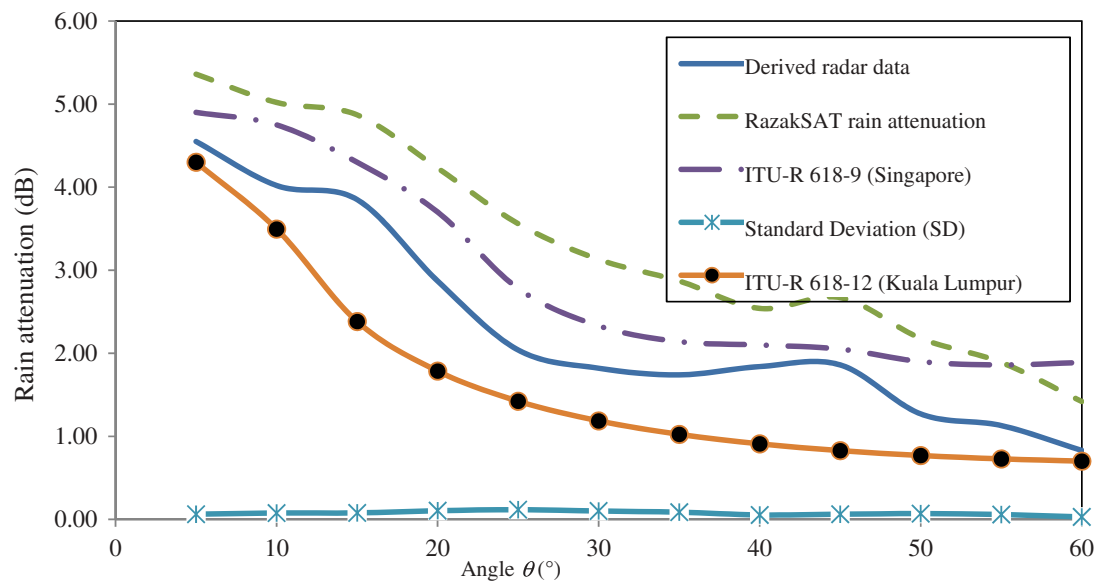

Figure 13. Rain attenuation from RazakSAT measurement, ITU-R calculations for Kuala Lumpur and Singapore, derived radar data, and the standard deviation.

$$
\mathrm{SD}=\sqrt{\frac{1}{N}\left(\sum_{i=1}^{N}\left(R^{\prime}-S\right)^{2}\right)},
$$

where $N$ is the number of samples, $R$ ' is the radar-derived attenuation, and $S$ is the average RazakSAT attenuation. Table 5 shows an example of the SD and percentage differences between radar-derived and RazakSAT attenuation measurements. Among the possible reasons for such discrepancies is the inapplicability of suitable formulations used in the calculations. Further investigations will be carried out in future works.

\section{Conclusion}

It is believed that radar has the potential to become a reliable technique in estimating rain attenuation for the Earth-space link. Comparisons to satellite link measurements have

Table 5. Standard deviation (SD) and percentage difference between radar-derived and RazakSAT rain attenuation measurements.

\begin{tabular}{lcccc}
\hline $\begin{array}{l}\text { Elevation } \\
\text { angle } \theta\left({ }^{\circ}\right)\end{array}$ & $\begin{array}{c}\text { Radar-derived rain } \\
\text { attenuation }(\mathrm{dB})\end{array}$ & $\begin{array}{c}\text { RazakSAT rain attenuation } \\
\text { measurement }(\mathrm{dB})\end{array}$ & $\begin{array}{c}\text { SD } \\
(\%)\end{array}$ & $\begin{array}{c}\text { Percentage } \\
\text { error }(\%)\end{array}$ \\
\hline 5 & 4.55 & 5.36 & 0.06 & 15.11 \\
10 & 4.02 & 5.02 & 0.08 & 19.92 \\
15 & 3.85 & 4.87 & 0.08 & 20.94 \\
20 & 2.87 & 4.23 & 0.10 & 32.15 \\
25 & 2.04 & 3.56 & 0.12 & 42.70 \\
30 & 1.82 & 3.13 & 0.10 & 41.85 \\
35 & 1.74 & 2.87 & 0.09 & 39.37 \\
40 & 1.84 & 2.54 & 0.05 & 27.56 \\
45 & 1.86 & 2.67 & 0.06 & 30.34 \\
50 & 1.27 & 2.18 & 0.07 & 41.74 \\
55 & 1.13 & 1.89 & 0.06 & 40.21 \\
60 & 0.83 & 1.22 & 0.03 & 31.97 \\
\hline
\end{tabular}


indicated that radar reflectivity values can be exploited as an estimator of rain attenuation. Radar is able to provide rainfall spatial information whereas this is simply not possible using only rain gauges. The values of rainfall rate derived from radar reflectivity can be estimated at instantaneous points along the slant path. With the assimilation of radar reflectivity, appropriate $Z-R$ relation, and specific attenuation relation, it is suggested that the likely attenuation during convective rain and/or stratiform rain events at any location and time can be predicted. This is important since such rain events are recurrent in tropical regions like Malaysia. From the analysis presented in this article, it is noted that improvements in rain attenuation estimation using radar data are required in order to achieve better prediction values. The new rain attenuation estimation procedure may be very important for satellite engineers and researchers in their efforts towards planning a realistic link budget estimation and set-up.

\section{Disclosure statement}

No potential conflict of interest was reported by the authors.

\section{Funding}

This work was supported by the Research Acculturation Grant Scheme (RAGS) 2013

\section{References}

Badron, K., A. F. Ismail, J. Din, and A. R. Tharek. 2009. "Rain Induced Attenuation Studies for V-Band Frequency in Tropical Regions." 2009 Loughborough Antennas \& Propagation Conference, November 16-17, 689-692.

Battan, L. J. 1973. Radar Observation of the Atmosphere, 324. John Wiley \& Sons, Ltd.

Bech, J., A. Magaldi, B. Codina, and J. Lorente. 2012. Effects of Anomalous Propagation Conditions on Weather Radar Observations. Accessed 23, 2014. www.intechopen.com

Dao, H., M. R. Islam, K. Al-Khateeb, and A. F. Ismail. 2012. "Analysis of Rain Fade Duration over Satellite-earth Path at Ku-Band in Tropics." 2012 International Conference on Computer and Communication Engineering (ICCCE), July 3-5, 953-956.

Doviak, R. J., and D. S. Zrnic. 1993. Doppler Radar and Weather Observation. 2nd ed. London: Academic Press.

Goldhirsh, J. 1976. "Attenuation of Propagation through Rain for an Earth-Satellite Path Correlated with Predicted Values Using Radar." IEEE Transactions on Antennas and Propagation 24 (6): 800-806. doi:10.1109/TAP.1976.1141423.

International Union of Telecommunications. 2013. ITU-R P.618-2013, Recommendation: Propagation Data and Prediction Methods Required for the Design of Earth-space Telecommunication Systems. France: ITU.

Kumar, L. S. 2009. "Slant-Path Rain Attenuation at Different Elevation Angles for Tropical Region." 7th International Conference on Information, Communications and Signal Processing, ICICS 2009, 18-21. doi:10.1109/ICICS.2009.5397706

Kumar, L. S., Y. H. Lee, J. X. Yeo, and J. T. Ong. 2011. "Tropical Rain Classification and Estimation of Rain from Z-R (Reflectivity-Rain Rate) Relationships." Progress in Electromagnetics Research B 32 (July): 107-127. doi:10.2528/PIERB11040402.

Ladd, D. N., C. L. Wilson, and M. Thurai. 1997. "Radar Measurements from Papua New Guinea and their Implications for TRMM PR Retrieval Algorithms." Geoscience and Remote Sensing, IGARSS'97, Remote Sensing - A Scientific Vision for Sustainable Development 4: 1648-1650. doi:10.1109/IGARSS.1997.609004

Marshal, J. S., and W. M. Palmer. 1948. "The Distribution of Raindrops with Size." Journal of Meteorology 5: 165-166. doi:10.1175/1520-0469(1948)005<0165:TDORWS>2.0.CO;2.

Mohr, C. G., and R. L. Vaughan. 1979. "An Economical Procedure for Cartesian Interpolation and Display of Reflectivity Factor Data in Three -Dimensional Space." Journal of Applied 
Meteorology 18: 661-670. doi:10.1175/1520-0450(1979)018<0661:AEPFCI >2.0.CO;2. May 1979.

RazakSAT. 2006. “Asian Surveying and Mapping.” Accessed January 11, 2014. http://web.archive. org/web/20070927185734/http://www.asmmag.com/ASM/content/2006/ASM_032/main_ news_5.html

Rinehart, R. 2001. Radar for Meteorologists. 3rd ed. 428 pp. Columbia, MO: Rinehart Publications. ISBN 0- 9658002-0-2

Roland, B. S. 2000. Meteorology for Scientist and Engineers. 2nd ed. 528 pp. Brooks Cole.

Savageot, H. 1992. Radar Meteorology. Massachusetts, USA: Artech House.

SIGMET. 1999. Configuring IRIS/Open Products. IRIS/Open User's Manual, Version 7.05, 7.17.98. SIGMET Inc.

Stutzman, W. L., T. Pratt, C. W. Bostian, and R. E. Porter. 1989. "Slant Path Attenuation Statistics Predicted From Dual Polarized Radar Data." Sixth International Conference on Antennas and Propagation, ICAP 89 (2): 216-219.

Tokay, A., and A. S. David. 1995. "Evidence from Tropical Raindrop Spectra of the Origin of Rain from Stratiform versus Convective Clouds." Journal of Applied Meteorology and Climatology 36: $355-371$.

Wilson, C. L., and J. Tan. 2001. "The Characteristics of Rainfall and Melting Layer in Singapore: Experimental Results from Radar and Ground Instruments." 11th Lntemational Conference on Antennas and Propagation 480: 852-856.

Yeo, J. X., Y.-H. Lee, L. S. Kumar, and J. T. Ong. 2012. "Comparison of S-Band Radar Attenuation Prediction With Beacon Measurements." IEEE Transactions on Antennas and Propagation 60 (10): 4892-4900. doi:10.1109/TAP.2012.2207346. 